\title{
Long-term versus short-term deformation processes at Tenerife (Canary Islands)
}

\author{
Pietro Tizzani, ${ }^{1}$ Andrea Manconi, ${ }^{1,2}$ Giovanni Zeni, ${ }^{1}$ Antonio Pepe, ${ }^{1}$ \\ Mariarosaria Manzo, ${ }^{1}$ Antonio Camacho, ${ }^{3}$ and Jose Fernández ${ }^{3}$ \\ Received 28 May 2010; revised 4 August 2010; accepted 2 September 2010; published 16 December 2010.
}

[1] Several geophysical investigations have identified that the Tenerife volcanic complex is affected by crustal deformation processes occurring at timescales of millions of years. Recently, space-based geodetic observations have also detected a short-term surface deformation, characterized by a broad subsidence pattern with maximum ground velocities of about $4 \mathrm{~mm} \mathrm{yr}^{-1}$. For the purpose of investigating the relationship between these long-term and short-term deformation processes, we performed an advanced fluid dynamic analysis (FDA). We first carried out a standard dimensionless FDA to discriminate the deformation style of Tenerife and found that, at million year timescales, basement flexure mainly controls its long-term structural evolution. Secondly, to highlight the driving forces of the short-term deformation process, we simulated a numerical FDA based on finite element models that include topography as well as vertical and lateral material heterogeneities. Our results show that the recent surface deformation is mainly caused by a progressive sagging of the denser (less viscous) core of the island onto the weaker (but more viscous) lithosphere. Moreover, over periods comparable to the hypothesized age of loading of the oceanic crust beneath Tenerife, this tendency would result in a total flexure of about $3-4 \mathrm{~km}$, which is in agreement with independent estimations based on geophysical analyses. Our study shows that a unitary physical model may explain both the deformation recorded in deep geological structures and the current active ground deformation processes occurring at the Tenerife volcano.

Citation: Tizzani, P., A. Manconi, G. Zeni, A. Pepe, M. Manzo, A. Camacho, and J. Fernández (2010), Long-term versus short-term deformation processes at Tenerife (Canary Islands), J. Geophys. Res., 115, B12412, doi:10.1029/2010JB007735.

\section{Introduction}

[2] Tenerife, the largest volcanic complex among the Canary Islands (Spain), is the result of the coalescence of several shield volcanoes [Martí et al., 1994; Ablay and Kearey, 2000]. Different hypotheses about the origins of Tenerife have been proposed over the past decades. Among the several theories, the most debated ones propose a hotspot or mantle plume [Pérez et al., 1994; Carracedo et al., 1998; Perlock et al., 2008; Dañobeitia and Canales, 2000], a region of compressional block faulting [Araña and Ortíz, 1991], a rupture propagating from the active Atlas Range [Anguita and Hernán, 1975], or a unifying model [Anguita and Hernán, 2000]. Since about $10 \mathrm{Ma}$ to the present, the ascent of mantle-derived basaltic magmas has been focused along two main rift zones, trending northeast and northwest, and on a third subsidiary rift trending south [Carracedo et al., 2007]. The oldest part of the island (the shield volcanic complex,

\footnotetext{
${ }^{1}$ Istituto per il Rilevamento Elettromagnetico dell'Ambiente, CNR, Napoli, Italy.

${ }^{2}$ Now at IRPI-CNR, Torino, Italy.

${ }^{3}$ Instituto de Astronomia y Geodesia, Consejo Superior de Investigaciones Científicas, Universidad Complutense de Madrid, Madrid, Spain.

Copyright 2010 by the American Geophysical Union. 0148-0227/10/2010JB007735
}

mostly submerged) was built upon a basement of submarine extrusive rocks, which outcrop west-southwest and northeast (see Figure 1). The Las Cañadas composite volcano (from more than $3.5 \mathrm{Ma}$ to $0.18 \mathrm{Ma}$ ) and the currently active TeidePico Viejo stratovolcano (from $0.18 \mathrm{Ma}$ to present) form the central volcanic complex. The latter mostly consists of lavas that evolved from basaltic to phonolitic composition, and it has been characterized by abundant explosive eruptions and several vertical collapses following the explosive withdrawal of shallow magma chambers (4-6 km deep), sporadically accompanied by lateral collapses [Martí et al., 1997]. Lava emissions from Teide-Pico Viejo and along the Las Cañadas caldera rim characterized the recent volcanic activity of Tenerife [Ancochea et al., 1990].

[3] Several authors have analyzed the geodynamic and tectonic processes affecting the Tenerife volcano and, more in general, the Canary Islands [Watts, 1994; Watts et al., 1997; Watts and Zhong, 2000; Collier and Watts, 2001; Minshull and Charvis, 2001]. The main results propose a complex interaction between the subvolcanic and regional structures at the Myr timescale, which produced a large flexure of the oceanic lithosphere [Minshull and Charvis, 2001], as confirmed by seismic and gravimetric studies [Watts et al., 1997; Araña et al., 2000; Gottsmann et al., 2006, 2008]. On the other hand, recent space-based geodetic observations based on 


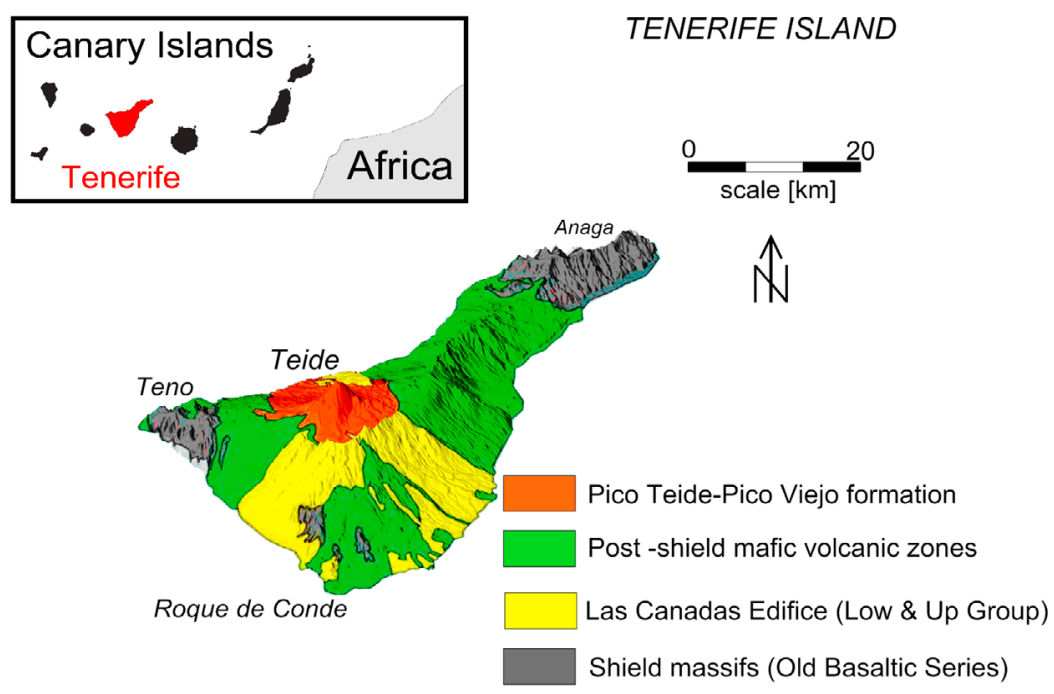

Figure 1. Sketch of the geological map of Tenerife Island (redrawn from Fernández et al. [2009]).

Differential Synthetic Aperture Radar Interferometry (DInSAR) and GPS measurements revealed, in the 1992-2005 period, a deformation pattern characterized by a broad subsidence with maximum velocities of about $4 \mathrm{~mm} \mathrm{yr}^{-1}$ [Fernández et al., 2009]. The understanding of possible relationships between the long-term deformations recorded in geological structures and the short-term deformations measured at the surface via geodetic techniques can be very important for understanding active volcano behavior. For this reason, this work aims at clarifying whether the long-term and short-term deformations observed at Tenerife might be explained by considering a unitary physical model. In the following, we first describe the approach used to discriminate the long-term deformation style of the Tenerife volcanic complex. Secondly, we extend the work done by Fernández et al. [2009], investigating the short-term surface deformation processes by means of advanced Finite Element (FE) models.

\section{Methods}

\subsection{Long-term Volcano Deformation Analysis}

[4] Gravitational processes in volcanic areas are mainly controlled by the rheologies of the substratum underlying the main edifices [Merle and Borgia, 1996; van Wyk de Vries and Borgia, 1996]. According to van Wyk de Vries and Matela [1998], the deformation style due to volcanic loading depends on the presence of a ductile layer beneath the volcano edifices, which might in turn cause substratum flexure, basement extrusion, or volcano spreading. More specifically, these studies propose the characterization of the deformation styles of volcanoes in different geodynamic contexts by considering a dimensionless Fluid Dynamic Analysis (FDA). The latter relates the geometrical and structural parameters of the volcano under consideration (such as the radius of the volcanic complex, the age of loading of the crust, the thickness and viscosity of the ductile layer, etc.; see details in van Wyk de Vries and Matela [1998]) to a set of dimensionless numbers $\left(\Pi_{\mathrm{a}}\right.$ and $\left.\Pi_{\mathrm{b}}\right)$ derived by the Buckingham $\Pi$ theorem [Buckingham, 1914, 1915].
[5] We analyzed the long-term deformation processes occurring at Tenerife by following the guidelines proposed by van Wyk de Vries and Matela [1998]. We calculated the dimensionless numbers $\Pi_{a}$ and $\Pi_{b}$ by integrating different geophysical data to constrain the structural parameters and the oceanic crust age of loading (see Table 1). Our dimensionless FDA places Tenerife in the field with low $\Pi_{\mathrm{a}}$ and $\Pi_{\mathrm{b}}$ values, defined as "flexure" (Figure 2). In particular, this result also remains constant when considering different values for the model parameters. Thus, our result suggests that "basement flexure" mainly controls the long-term structural evolution of the Tenerife volcanic complex at the Myr timescale.

\subsection{Short-term Volcano Deformation Analysis}

[6] Fernández et al. [2009], by considering GPS and Small Baseline Subset (SBAS) DInSAR analyses [Berardino et al., 2002], detected a broad surface deformation pattern at Tenerife characterized by subsidence with maximum velocities of about $4 \mathrm{~mm} \mathrm{yr}^{-1}$. To model this data, they proposed a simplified analytical approach (mass loading of a point source embedded in a layered medium, with a top elastic layer overlapping a viscoelastic half-space) and interpreted the ground displacements as gravitational sinking caused by the denser core of the island descending onto the weaker lithosphere. However, while such a model seems to reasonably fit the observed displacements and is substantially in agreement with the geodynamic scenario, this analytical approach fails to accurately interpret the spatial variability of the deformation signal. This lack of fit is probably related to the simplified modeling settings (e.g., point source assumption, flat surface, lateral homogeneity, etc.) and/or to its physical assumptions (elasticity, viscoelasticity). We extended the analysis presented by Fernández et al. [2009] and considered FE models that include the topography of Tenerife as well as the vertical and lateral variations of the physical characteristics of the crust and the upper mantle. Because the ground displacements detected at Tenerife are mainly due to tectonic strain, the deformation processes can be well-represented in a fluid dynamics context [Kennett and Bunge, 2008]. Moreover, the displacements show a linear dependence with time (see Figures $2 \mathrm{~b}-2 \mathrm{f}$ of 
Table 1. Dimensionless FDA Parameters ${ }^{\mathrm{a}}$



${ }^{a}$ Model Groups A, B, and C were assembled using three different values of crust elastic thickness (EP Layer) and loading time $(t)$ according to Watts [1994], Filmer and McNutt [1989], and Dañobeitia et al. [1994], respectively. The thickness of the ductile layer (EP Layer), the cohesion of the elastoplastic layer and the volcano edifice $\left(\mathrm{C}_{\mathrm{v}}\right)$, and the model viscosity $(\mu)$ were defined by considering the study of Watts and Zhong [2000], whereas geometric properties were constrained using information derived by bathymetric data and seismic profiles [Watts, 1994; Watts and Masson, 2001; Krastel et al., 2001].

${ }^{\mathrm{b}}$ Data from Watts and Masson [2001] and Krastel et al. [2001].

${ }^{\mathrm{c}}$ The bottom of the ductile layer is fixed at a depth of $125 \mathrm{~km}$, according to Watts and Zhong [2000].

${ }^{\mathrm{d}} \mathrm{EP}$-Layer, $20 \pm 5 ; t, 8 \pm 5$; Watts [1994].

${ }^{e}$ EP-Layer, $48 \pm 3 ; t, 10 \pm 3$; Filmer and McNutt [1989].

${ }_{\mathrm{f}}^{\mathrm{E}} \mathrm{P}-\mathrm{L}$ ayer, $35 \pm 5 ; t, 20 \pm 3$; Dañobeitia et al. [1994].

Fernández et al. [2009]); thus, we can assume a steady state viscous flow (Newtonian fluid) in our FDA and solve for the incompressible Navier-Stokes set of differential equations

$$
\begin{gathered}
-\nabla \cdot \eta\left(\nabla \mathbf{u}+(\nabla \mathbf{u})^{T}\right)+\rho(\mathbf{u} \cdot \nabla) \mathbf{u}+\nabla p=\mathbf{F} \\
\nabla \cdot \mathbf{u}=0
\end{gathered}
$$

where $\mathbf{u}$ is the velocity vector, $\mathbf{F}$ is the body force term, $\rho$ is the density, $p$ is the pressure, and $\eta$ is the dynamic viscosity (hereafter referred to as viscosity). We first simplified our simulations by considering an axisymmetric domain. The model dimensions were $160 \mathrm{~km}$ and $85 \mathrm{~km}$ in the radial $(r)$ and vertical $(z)$ directions, respectively. The distribution of densities was derived from both seismic and gravity data [Watts et al., 1997; Camacho et al., 2000; Camacho et al., 2002; Gottsmann et al., 2008]. The density distribution was included within the FE models as a two-dimensional (2D) function with a $500 \times 500 \mathrm{~m}$ resolution $\left(\rho_{(r, z)}\right)$, which also considers an approximated topographic profile of the island above the seafloor (see Figure 3). The domain discretization (about 6000 triangular elements) was validated through several resolution tests, which evidenced that the use of a finer mesh would affect the results by less than $1 \%$.

[7] Body forces on the domain are mostly due to the vertical component of lithostatic loading; thus,

$$
F_{(r)}=0, \quad F_{(z)}=-\rho_{(r, z)} \cdot g,
$$

where $g$ is the acceleration due to gravity $\left(9.81 \mathrm{~m} \mathrm{~s}^{-2}\right)$. As boundary conditions, we set the pressure reference level $(p=$ 0 ) at the top of the simulated volcano topographic surface (see inset in Figure 3), and, because of the incompressibility and stationarity assumptions of our analysis, we assumed velocities of $u_{(r)}=u_{(z)}=0$ on all model boundaries, excluding the symmetry axis. These constraints allowed for momentum conservation in the analyzed domain and, as the area of 




Figure 2. Plot of $\Pi_{\mathrm{a}}$ vs. $\Pi_{\mathrm{b}}$, illustrating the fields for flexure-dominated, spreading-dominated and extrusion-dominated systems (after van Wyk de Vries and Matela [1998]). The values calculated in this study for the Tenerife volcano are represented by red, blue, and green triangles which refer to models $\mathrm{A}, \mathrm{B}$, and $\mathrm{C}$, respectively (see parameters in Table 1).

interest is far enough from the boundaries, did not affect the FE modeling results.

[8] The viscosity distribution was evaluated through an advanced procedure that allowed the implementation of the FE models within nonlinear optimization algorithms [Manconi et al., 2010]. With this approach, we searched for the best fit viscosity model explaining the observed surface deformation velocities. We first allowed the algorithm to search for simplified homogeneous and vertically layered (crust, upper mantle, lower mantle) viscosity models. Secondly, we also allowed for vertical and lateral heterogeneities in the viscosity distribution associated with the 2D density function defined a priori (Figure 3). The model velocities were evaluated at the topographic surface, projected along the satellite line-of-sight (LOS), and compared with the measured SBAS-DInSAR data. The best fit viscosity model was finally selected by considering the RootMean-Square (RMS) error as the cost function.

[9] In Figure 4, we show the LOS ground velocities resulting from the FE models versus the velocities measured via the SBAS-DInSAR analysis on a profile along the radial distance. We note that the solutions for the homogeneous case, as well as those calculated within models that consider simplified vertical layering in the viscosity distribution, fit the deformation pattern within the expected accuracies, although they are not able to suitably explain the lateral variability of the deformation signal. This finding is in agreement with the analytical solutions proposed by Fernández et al. [2009]. In contrast, when horizontal and vertical variations of viscosity are also included within the
FE models, the deformation pattern is more accurately represented. This is also confirmed by the lower value of the RMS associated with the heterogeneous FE models. In particular, the best fit viscosity distribution derived by our optimization procedure is reported in Figure 5. Interestingly, while the vertical viscosity contrasts appear not to be very high $\left(\sim 5 \times 10^{22}\right.$ versus $\sim 10^{23} \mathrm{~Pa}$ s for the upper mantle and the oceanic crust, respectively), the viscosity strongly varies laterally by about two orders of magnitude (from $\sim 1.2 \times$ $10^{21} \mathrm{~Pa} \mathrm{~s}$ for the (denser) cumulitic complex to $\sim 10^{23} \mathrm{~Pa} \mathrm{~s}$ for the oceanic crust).

[10] The axisymmetric approximation of the abovedescribed FE models might be considered as an oversimplification because Tenerife has a complex triangular shape, and the analysis of a single profile might be misleading. On the basis of this consideration, we implemented a threedimensional (3D) forward model considering the 3D density structure derived again by the seismic and gravity data, whereas the viscosity distribution was constrained through the best fit heterogeneous model obtained within the optimization procedure. Moreover, in the 3D case, we also simulated a more realistic topographic relief of the volcanic complex by implementing the digital elevation model $(\mathrm{DEM})(90 \times 90 \mathrm{~m})$ derived from the Shuttle Radar Topography Mission (SRTM) (Figure 6a). The difference between the observed and simulated LOS-projected velocities shows that the $3 \mathrm{D}$ model is able to suitably explain the features of the surface deformation related to tectonic strain in the volcanic environment (Figures 6b-6d). This good fit occurs despite the $3 \mathrm{D}$ viscosity model being constrained by 




Figure 3. Setup of the axisymmetric FE model used in the numerical optimization. The density model (color bar) is derived from gravimetric and seismic data [Watts et al., 1997; Gottsmann et al., 2008]. The dashed white curve indicates the Moho discontinuity [Longpré et al., 2008, and references therein]. The inset describes the boundary and the loading conditions of the FE model (see text for more details).

considering the results of the axisymmetric models. The larger values of residuals are mostly located in places where an anthropogenic component of the surface deformation has previously been recognized (see also Figure 3f of Fernández et al. [2009]).

\section{Discussion and Conclusions}

[11] In this work, we analyzed the active deformation processes at the Tenerife volcano. In particular, to highlight the origin of the driving forces that controlled the structural evolution of the volcano and the currently observed deformation field, we carried out a two-scale FDA. We first performed a dimensionless FDA by applying the Buckingham $\Pi$ theorem and found that basement flexure controls the long-term structural evolution of Tenerife, thus confirming the general hypothesis proposed by van Wyk de Vries and Matela [1998] for the deformation style of the Canary Islands. Secondly, by considering heterogeneous axisymmetric FE models within an advanced nonlinear optimization procedure, we showed that the surface deformation observed in the 1992-2005 period can be explained by a progressive sagging of the denser (less viscous) core of the island (cumulitic complex) onto the weaker (but more viscous) lithosphere. In addition, the implementation of our results in a 3D forward model shows that the spatial variability of the deformation signal is well-compensated by the lateral variation of the crustal and upper mantle rheological properties. The latter seems to control both the amplitude and the spatial orientation of the ground velocity field. Indeed, the model in general fits very well with the detected broad subsidence, while the localities with larger residuals are mainly associated with man-made deformation features, such as water exploitation [see Fernández et al., 2009]. Moreover, the surface deformation is not constrained by the Las Cañadas caldera rim, as the deformation continues well beyond its rim (see Figures 4 and 6b). After the removal of the model, some localized residuals still remain in the caldera (P3 in Figure 6d), but this feature is probably associated with the local dynamics of the caldera itself. Indeed, rocks within the Las Cañadas caldera can present very low viscosities in the core due to hydrothermal alterations at shallow depths and can also react to the load of the Teide volcano as well as to the deep sagging of the cumulitic complex [Merle et al., 2010]. On the other hand, the main source of the deformation resulting from our models appears to be broader and is underway at depths up to $10-15 \mathrm{~km}$ below sea level. The low viscosity values found in our 




Figure 4. Comparison between surface deformation velocities measured via the SBAS-DInSAR (black triangles) and those obtained via the FE optimization procedure for homogeneous (green curve), layered (blue curve), and heterogeneous viscosity models (red curve). The dashed black curve represents the topographic profile along the considered radial distance. The RMS values of the three models as well as the accuracy of the deformation velocities retrieved via the SBAS-DInSAR analysis are reported in the upper left and bottom right corners, respectively. The RMS values reveal that the heterogeneous model better fits the observed velocities.

model at these levels might be the result of anomalous thermal conditions of the rocks that form the denser core of the island, which are probably associated with the upper mantle magma plumbing system of Tenerife [Longpré et al., 2008].

[12] Focusing on the details of the velocity field at depth (Figure 7), we note that its spatial orientation reveals a lateral mass migration that accompanies the central subsidence of the crust beneath the cumulitic complex. Furthermore, the sagging effects of the cumulitic complex are markedly reduced where a higher value of the upper mantle viscosity is encountered (about $1 \mathrm{~mm} \mathrm{yr}^{-1}$ at a depth of $10-15 \mathrm{~km}$ versus $4 \mathrm{~mm} \mathrm{yr}^{-1}$ at the surface). We speculate that this tendency might encourage the driving forces responsible for the basement flexure observed at a larger spatial scale. If we consider that the Tenerife volcanic complex was largely
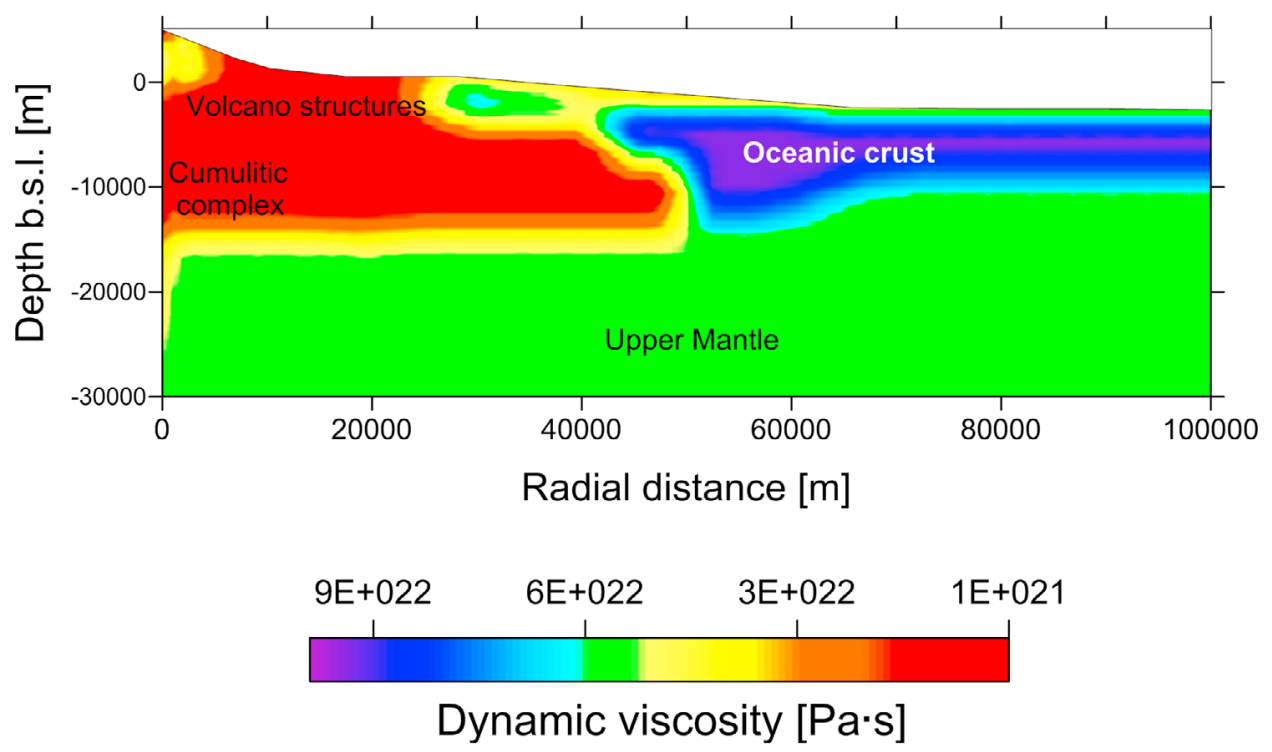

Figure 5. The best fit viscosity model obtained via the FE optimization procedure. 

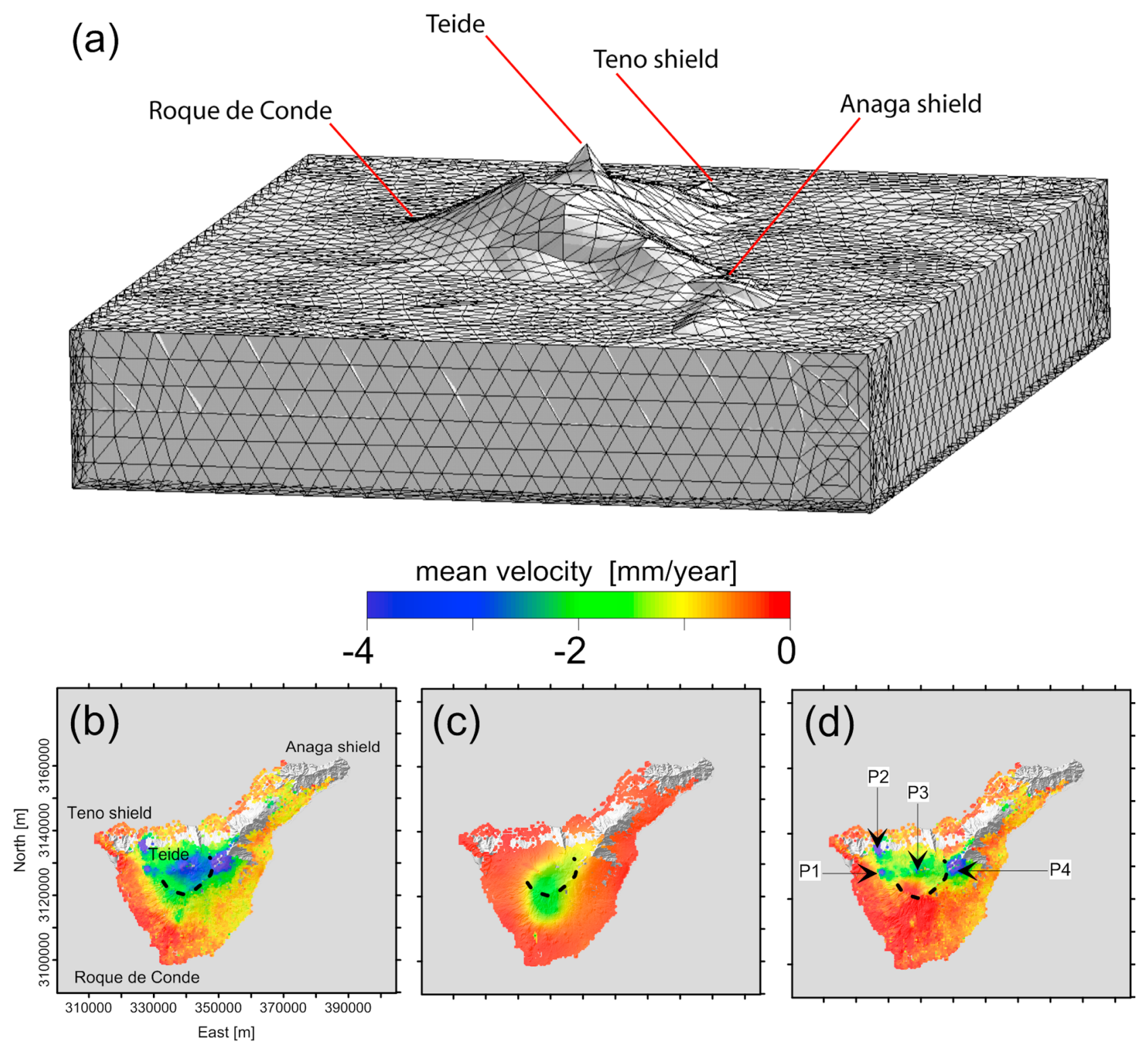

Figure 6. Results of the 3D finite element model. (a) Mesh of the 3D FE model. The model includes the realistic topographic relief of Tenerife Island derived by the SRTM $(90 \times 90 \mathrm{~m}) \mathrm{DEM}$, the 3D density structure derived from seismic and gravity data, as well as the 3D viscosity model derived by our optimization analysis. The loading and boundary conditions are the same as those defined for the axisymmetric FE model (see the inset in Figure 3). (b) SBAS-DInSAR velocity map (resampled to a resolution of $500 \times 500 \mathrm{~m}$ ) superimposed on the DEM of Tenerife. (c) Modeled velocities retrieved from the 3D FE model and projected along the line-of-sight of the satellite. (d) Difference between Figures $6 \mathrm{~b}$ and $6 \mathrm{c}$. P1, P2, and P4 identify localized residuals related to anthropogenic deformations [see Fernández et al., 2009] while P3 indicates residuals related to local dynamics of the Las Cañadas caldera and the Teide-Pico Viejo stratovolcano (see section 3 for details).

built between 11.9 and 3.9 Ma [Longpré et al., 2009, and references therein], and taking the latter as the start time of loading of the oceanic crust while considering a stationary trend of about $1 \mathrm{~mm} \mathrm{yr}^{-1}$, we obtain a total flexure of the lithosphere in the range of $3-4 \mathrm{~km}$. These values are rather compatible with independent estimations of the flexure of the lithosphere under Tenerife performed via geophysical analyses (about $3.5 \mathrm{~km}$; Watts et al. [1997], Collier and Watts [2001]). We are aware that the deformations on such timescales are probably affected by nonstationary processes and that events such as the growth and collapse of portions of the edifice may cause large variations from a linear trend. However, it is interesting to remark that starting from the observation of the deformation processes via the SBAS-DInSAR time series over a 10-15 year timescale, our modeling strategy provided values rather compatible with the total flexure of the lithosphere beneath the Tenerife volcanic complex, a process that can be observed at a 


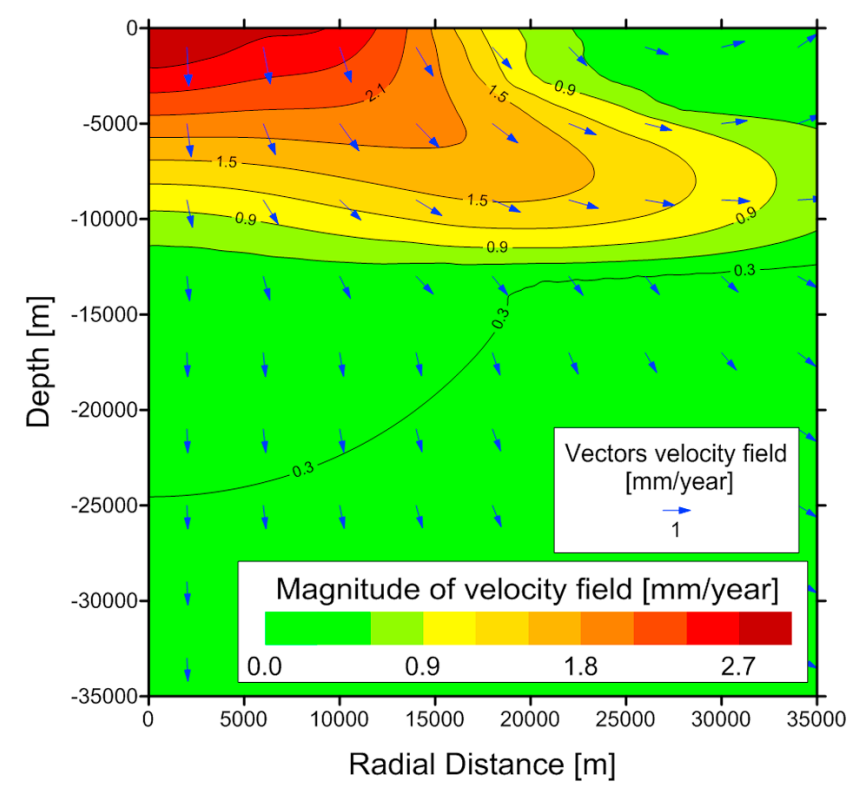

Figure 7. Distribution of the modeled velocity field in the upper crust beneath the volcano edifice. The blue arrows indicate the field direction and the color scale indicates the magnitude of the computed field.

Myr timescale. Moreover, the performed two-scale FDA revealed that at Tenerife it is possible to consider a unitary physical model to explain both the long-term deformation recorded in deep geological structures and the currently active ground deformation processes. In this context, our short-term analysis can be considered as a sort of experimental laboratory for the understanding of long-term structural evolution starting from recent geodetic observations.

[13] Our results might also be very useful for future analyses of deformation processes in other active volcanic areas presenting similar characteristics. For example, beneath the Hawaiian chain, a broad flexure of the crust and lithosphere has also been evidenced by geophysical analyses, in conjunction with idealized elastic models of flexure [Watts and ten Brink, 1989; Wessel, 1993]. Moreover, recent analyses have shown that the load of the volcanic complex in the island of Hawaii might control the seismic occurrences as well as the ascent of magmas [McGovern, 2007]. In this context, the availability of spatially and temporally dense surface deformation time series, as those achievable with the SBAS-DInSAR approach, as well as information on the volcanic structures derived from independent geophysical observations, might be useful within a numerical FDA to study the relationship between long-term and short-term deformation processes of the Hawaiian volcanic complex. However, the deformation signal related to a potential sagging of the central complex onto the oceanic crust might not be as clearly identifiable as in the case of the Tenerife volcano. Indeed, earthquakes, inflation/ deflation of shallow magmatic reservoirs, dike intrusions and/or eruptions, and thus the unrest of volcanoes, such as Mauna Loa and Kilauea on the island of Hawaii, largely affect the measured short-term displacements [Amelung et al., 2007; Montgomery-Brown et al., 2010].
[14] As a final remark, we would like to stress that the joint analysis of long-term and short-term volcanic deformation processes may provide a significant improvement in the understanding of the behavior of volcanoes. Moreover, because the compression regime induced by the flexure of the oceanic crust under the action of volcanic loading and the sagging of the dense core of the island can affect the future volcanic activity [van Wyk de Vries and Borgia 1996], the results of this study might also be relevant for future hazard assessment in active volcanic areas.

[15] Acknowledgments. We thank R. Lanari (IREA-CNR) for providing motivation and useful suggestions; V. Acocella (Università Roma 3), M. Battaglia (University of Roma "La Sapienza") and T. R. Walter (GFZ Potsdam) for fruitful discussions. The comments of the Associate Editor and of two anonymous reviewers for their comments that improved the quality of the manuscript. Research by AGC and JF was supported by the Spanish MICINN projects GEOMOD (CGL2005-05500-C02) and PEL2G (CGL2008-06426-C01-01/BTE) and was done in the framework of the Moncloa Campus of International Excellence (UCM-UPM). The FE models presented in this work were implemented using the commercial package

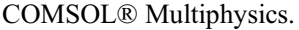

\section{References}

Ablay, G., and P. Kearey (2000), Gravity constraints on the structure and volcanic evolution of Tenerife, Canary Islands, J. Geophys. Res., 105, 5783-5796, doi:10.1029/1999JB900404.

Amelung, F., S.-H. Yun, T. R. Walter, and P. Segall (2007), Stress control of deep rift intrusion at Mauna Loa volcano, Hawaii, Science, 316, 1026 1030, doi:10.1126/science.1140035.

Ancochea, E., J. M. Fuster, E. Ibarrola, A. Cendrero, J. Coello, F. Henan, J.

M. Cantagrel, and C. Hamond (1990), Volcanic evolution of the island of

Tenerife (Canary Islands) in the light of new K-Ar data, J. Volcanol. Geotherm. Res., 44, 231-249.

Anguita, F., and F. Hernán (1975), A propagating fracture model versus a hotspot origin for the Canary Islands, Earth Planet. Sci. Lett., 27, 11-19, doi:10.1016/0012-821X(75)90155-7.

Anguita, F., and F. Hernán (2000), The Canary Islands origin: A unifying model, J. Volcanol. Geotherm. Res., 103, 1-26.

Araña, V., and R. Ortíz (1991), The Canary Islands: Tectonics, magmatism, and geodynamic framework, in Magmatism in Extensional Structural Settings: The Phanerozoic African Plate, edited by A. B. Kampunzu and R. T. Lubala, pp. 209-249, Springer-Verlag, Berlin.

Araña, V., A. G. Camacho, A. Garcia, F. G. Montesinos, I. Blanco, R. Vieira, and A. Felpeto (2000), The internal structure of Tenerife (Canary Islands) based on gravity, aeromagnetic, and volcanological data, J. Volcanol. Geotherm. Res., 103, 43-64.

Berardino, P., G. Fornaro, R. Lanari, and E. Sansosti (2002), A new algorithm for surface deformation monitoring based on small baseline differential SAR interferograms, IEEE Trans. Geosci. Remote Sens., 40, 2375-2383.

Buckingham, E. (1914), On physically similar systems: Illustrations of the use of dimensional equations, Phys. Rev., 4, 345-376.

Buckingham, E. (1915), The principle of similitude, Nature, 96, 396-397. Camacho, A. G., F. G. Montesinos, and R. Vieira (2000), Gravity inversion by means of growing bodies, Geophysics, 65, 95-101, doi:10.1190/ 1.1444729 .

Camacho, A. G., F. G. Montesinos, and R. Vieira (2002), A 3D gravity inversion tool based on exploration of model possibilities, Comput. Geosci., 28, 191-204, doi:10.1016/S0098-3004(01)00039-5.

Carracedo, J. C., S. Day, H. Guillou, E. Rodríguez, J. A. Canas, and F. J. Pérez (1998), Hotspot volcanism close to a passive continental margin, Geol. Mag., 135, 591-604.

Carracedo, J. C., E. Rodrìguez Badiola, H. Guillou, M. Paterne, S. Scaillet, F. J. Perez Torrado, R. Paris, U. Fra-Paleo, and A. Hansen (2007), Eruptive and structural history of Teide Volcano and rift zones of Tenerife, Canary Islands, Geol. Soc. Am. Bull., 119, 1027-1051, doi: 10.1130/ B26087.1.

Collier, J. S., and A. B. Watts (2001), Lithospheric response to volcanic loading by the Canary Islands: Constraints from seismic reflection data in their flexural moats, Geophys. J. Int., 147, 660-676.

Dañobeitia, J. J., and J. P. Canales (2000), Magmatic underplating in the Canary Archipelago, J. Volcanol. Geotherm. Res., 103, 27-41. 
Dañobeitia, J. J., J. P. Canales, and G. A. Dehghani (1994), An estimation of the elastic thickness of the lithosphere in the Canary Archipelago using admittance function, Geophys. Res. Lett., 21, 2649-2652, doi:10.1029/ 94GL02552.

Fernández, J., et al. (2009), Gravity-driven deformation of Tenerife measured by InSAR time series analysis, Geophys. Res. Lett., 36, L04306, doi:10.1029/2008GL036920.

Filmer, P. E., and M. K. McNutt (1989), Geoid anomalies over the Canary Islands group, Mar. Geophys. Res., 11, 77-87.

Gottsmann, J., L. Wooller, J. Martì, J. Fernández, A. G. Camacho, P. J. Gonzalez, A. Garcia, and H. Rymer (2006), New evidence for the reawakening of Teide volcano, Geophys. Res. Lett., 33, L20311, doi:10.1029/ 2006GL027523.

Gottsmann, J., A. Camacho, L. Wooller, J. Martì, J. Fernández, A. Garcia, and H. Rymer (2008), Shallow structure beneath the central volcanic complex of Tenerife from new gravity data, Phys. Earth. Planet. Inter., $168,212-230$.

Krastel, S., H.-U. Schmincke, C. L. Jacobs, R. Rihm, T. P. Le Bas, and B. Alibés (2001), Submarine landslides around the Canary Islands, J. Geophys. Res., 106, 3977-3997, doi:10.1029/2000JB900413.

Kennett, B. L. N., and H.-P. Bunge (2008), Geophysical Continua, Cambridge University Press, Cambridge, U. K.

Longpré, M.-A., V. R. Troll, and T. H. Hansteen (2008), Upper mantle magma storage and transport under a Canarian shield-volcano, Teno, Tenerife (Spain), J. Geophys. Res., 113, B08203, doi:10.1029/ 2007JB005422.

Longpré, M.-A., V. R. Troll, T. R. Walter, and T. H. Hansteen (2009), Volcanic and geochemical evolution of the Teno massif, Tenerife, Canary Islands: Some repercussions of giant landslides on ocean island magmatism, Geochem. Geophys. Geosyst., 10, Q12017, doi:10.1029 2009GC002892.

Manconi, A., S. Pepe, P. Tizzani, G. Solaro, G. Zeni, and R. Lanari (2010), Numerical Inversion of SBAS-DInSAR time series, Geophys. Res. Abstr., 12, EGU2010-11877.

Martí, J., J. Mitjavila, and V. Araña (1994), Stratigraphy, structure, and geochronology of the Las Cañadas Caldera (Tenerife, Canary Islands), Geol. Mag., 131, 715-727.

Martí, J., M. Hurlimann, G. J. Ablay, and A. Gudmundsson (1997), Vertical and lateral collapses on Tenerife (Canary Islands) and other volcanic ocean islands, Geology, 25, 879-882.

McGovern, P. J. (2007), Flexural stresses beneath Hawaii: Implications for the October 15, 2006, earthquakes and magma ascent, Geophys. Res. Lett., 34, L23305, doi:10.1029/2007GL031305.

Merle, O., and A. Borgia (1996), Scaled experiments of volcanic spreading, J. Geophys. Res., 101, 13,805-13,817.

Minshull, T. A., and P. Charvis (2001), Ocean island densities and models of lithospheric flexure, Geophys. J. Inter., 145, 731-739, doi:10.1046/ j.0956-540x.2001.01422.x.
Montgomery-Brown, E. K., D. K. Sinnett, M. Poland, P. Segall, T. Orr, H. Zebker, and A. Miklius (2010), Geodetic evidence for en echelon dike emplacement and concurrent slow slip during the June 2007 intrusion and eruption at Kīlauea volcano, Hawaii, J. Geophys. Res., 115, B07405, doi:10.1029/2009JB006658.

Pérez, N. M., H. Wakita, S. Nakai, Y. Sano, and S. N. Williams (1994), $3 \mathrm{He} / 4 \mathrm{He}$ isotopic ratios in volcanic hydrothermal discharges from the Canary Islands, Spain: Implications on the origin of the volcanic activity, Mineral. Mag., 58A, 709-710.

Perlock, P. A., P. J. González, K. F. Tiampo, G. Rodriguez-Velasco, S. Samsonov, and J. Fernández (2008), Time evolution of deformation using time series of differential interferograms: Application to La Palma Island (Canary Islands), Pure Appl. Geophys., 165, 1531-1554, doi:10.1007/s00024-004-0388-7.

van Wyk de Vries, B., and A. Borgia (1996), The role of basement in volcano deformation, Geol. Soc. Spec. Publ., 110, 95-110, doi:10.1144/ GSL.SP.1996.110.01.07.

van Wyk de Vries, B., and R. Matela (1998), Styles of volcano-induced deformation: Numerical models of substratum flexure, spreading, and extrusion, J. Volcanol. Geotherm. Res., 81, 1-18, doi:10.1016/ S0377-0273(97)00076-0.

Watts, A. B. (1994), Crustal structure, gravity anomalies, and flexure of the lithosphere in the vicinity of the Canary Islands, Geophys. J. Inter., 119 648-666.

Watts, A. B., and D. G. Masson (2001), New sonar evidence of recent catastrophic landslides on the north flank of Tenerife, Canary Islands, Bull. Volcanol., 63, 8-19, doi:10.1007/s004450000119.

Watts, A. B., and U. S. ten Brink (1989), Crustal structure, flexure, and subsidence history of the Hawaiian Islands, J. Geophys. Res., 94, 10,473-10,500.

Watts, A. B., and S. Zhong (2000), Observations of flexure and the rheology of the oceanic lithosphere, Geophys. J. Inter., 142, 855-875.

Watts, A. B., C. Peirce, J. Collier, R. Dalwood, J.-P. Canales, and T. J. Henstock (1997), A seismic study of lithospheric flexure at Tenerife, Canary Islands, Earth Planet. Sci. Lett., 146, 431-448, doi:10.1016/ S0012-821X(96)00249-X.

Wessel, P. (1993), A re-examination of the flexural deformation beneath the Hawaiian Islands, J. Geophys. Res., 98, 12,177-12,190.

A. Camacho and J. Fernández, Instituto de Astronomia y Geodesia, Consejo Superior de Investigaciones Científicas, Universidad Complutense de Madrid, Ciudad Universitaria, Plaza de Ciencias, 3, ES-28040, Madrid, Spain

A. Manconi, IRPI-CNR, Strada delle Cacce 73, I-10135 Torino, Italy.

M. Manzo, A. Pepe, P. Tizzani, and G. Zeni, Istituto per il Rilevamento Elettromagnetico dell'Ambiente, CNR, Via Diocleziano, 328, IT-80124, Napoli, Italy. (tizzani.p@irea.cnr.it) 